\title{
Comparison of Prognosis in Types 1 and 2 Papillary Renal Cell Carcinoma and Clear Cell Renal Cell Carcinoma in T1 Stage
}

\author{
Jaehoon Lee, Han Kyu Chae, Wonchul Lee, Wook Nam, Bumjin Lim, \\ Se Young Choi, Yoon Soo Kyung, Dalsan You, In Gab Jeong, Cheryn Song, \\ Bumsik Hong, Jun Hyuk Hong, Hanjong Ahn, Choung-Soo Kim
}

Department of Urology, Asan Medical Center, University of Ulsan College of Medicine, Seoul, Korea

Purpose: We compared subtypes of papillary renal cell carcinoma (pRCC; types 1 and 2) and clear cell renal cell carcinoma (ccRCC) in patients with T1-stage RCC to analyze the impact of the subtype on oncological outcomes.

Materials and Methods: This paper reviewed 75 patients with pRCC and 252 patients with ccRCC at T1-stage from 1998-2012. Thus, we assessed the impact of subtype on oncologic outcomes among patients with T1-stage RCC. We used Kaplan-Meier analysis to estimate the overall survival and recurrence-free survival The median follow-up duration was 95 months (interquartile range, 75.4-119.3 months).

Results: The 5-year recurrence-free survivals of pRCC and cCRCC were $95.4 \%$ and $97.6 \%$, respectively. pRCC is worse than $c c R C C$ in terms of recurrence-free survival $(p=0.008)$ and there was no significant difference in the overall survival between $p R C C$ and $c c R C C(p=0.32)$. In addition, there was no significant statistical difference between type 1 pRCC and type 2 pRCC in terms of either recurrence-free survival $(p=0.526)$ or overall survival $(p=0.701)$. Age (hazard ratio $[H R], 1.069 ; p<0.001)$ and recurrence $(H R, 4.93 ; p<0.001)$ were predictors of overall survival. Only tumor size $(H R, 1.071 ; p=0.004)$ was predictors in the case of cancer specific survival in the multivariate analysis.

Conclusions: Among patients with T1-stage RCC, recurrence after surgery was more common in pRCC than ccRCC. The subtype of pRCC (types 1 and 2) had no impact on the recurrence-free survival or overall survival. (Korean J Urol Oncol 2018;16:119-125)

Key Words: Renal cell carcinoma $\cdot$ Histologic subtype $\cdot$ Recurrence $\cdot$ Survival $\cdot$ Prognosis

\section{INTRODUCTION}

Renal cell carcinoma (RCC) constitutes approximately $2 \%-$

Received September 10, 2018, Revised October 17, 2018,

Accepted October 18, 2018

Corresponding Author: Choung-Soo Kim

Department of Urology, Asan Medical Center, 88 Olympic-ro

43-Gil, Songpa-gu, Seoul 05505, Korea

E-mail: cskim @amc.seoul.kr

Tel: +82-2-3010-3734, Fax: +82-2-477-8928

ORCID code: https://orcid.org/0000-0002-7464-3207
$3 \%$ of all cancers, and its highest occurrence rate is in western countries. ${ }^{1}$ The current understanding of the pathogenesis of renal neoplasm has been established by World Health Organization classification ${ }^{2}$ and $\mathrm{Mainz}^{3}$ and Heidelberg classifications. ${ }^{4}$ RCC is classified as several subtypes according to different histological and genetic characteristics, and each subtype has different prognostic implications. RCC subtypes are classified as clear cell (ccRCC), papillary (pRCC), chromophobe, collecting duct, or as unclassified RCC according to Heidelberg classification. Papillary RCC accounts for $20 \%$ of all RCC cases; it is a heterogeneous disease with different histologic features and 2018 (C) Copyright The Korean Urological Oncology Society and The Korean Prostate Society. All Rights Reserved. 
displays variations in terms of disease progression and oncologic outcomes. The trisomy of chromosomes 3q, 7, 8, 12, 16, 17, and 20 and the loss of the $\mathrm{Y}$ chromosome are the most consistent genetic alterations. ${ }^{5}$ Traditionally, pRCC is further sub-classified as basophilic type 1 (small cell) and eosinophilic type 2 (large cell). Type 1 pRCCs have papillary structures that are lined by a simple cuboidal epithelium and foamy macrophages within papillary cores, and these have low-grade nuclei. Meanwhile, type 2 pRCCs have papillary structures lined by a pseudostratified epithelium with an abundant eosinophilic cytoplasm and show large high-grade nuclei. Although the prognostic significance of subtypes has been reviewed in several comparative studies, the results are currently inconsistent. Several studies have shown that type 2 pRCCs metastasize and frequently lead to patient death, so some authors have identified histologic subtypes as a prognostic factor; however, some others have not. ${ }^{6-10}$ Linehan et al. ${ }^{11}$ took a comprehensive genomics approach to characterizing the biologic components of papillary RCC. The CpG island methylator phenotype was observed in a distinct subgroup of type 2 pRCCs; this group of type 2 pRCCs has a mutation of the gene that encodes fumarate hydratase and poor survival. Yamanaka et al. ${ }^{12}$ compared 35 patients who were treated with radical surgery and who had been pathologically diagnosed as pRCC in April 1994-June 2004. Although previous studies reported favorable survival among patients with type $1 \mathrm{pRCC}$ compared to type $2 \mathrm{pRCC}$, this study indicates almost similar clinicopathological features including prognosis between the two groups of pRCC (types 1 and 2). Previous multivariate analysis with pRCCs failed to reveal any prognostic differences between histological subtypes. ${ }^{9,10,13-15}$ Still, it remains uncertain whether the histological subtype of $\mathrm{RCC}$ is an independent prognostic factor. Further, almost all studies have been conducted in western countries. Thus far, no study has compared the impact of the histological subtype of pRCC on oncologic outcomes limited to the T1-stage population. This single-center study's objective was to compare oncologic outcomes (recurrence-free survival and overall survival) between pRCC subtypes (types 1 and 2) and ccRCC in the T1stage.

\section{MATERIALS AND METHODS}

\section{Patient population}

This study was approved by the Institutional Review Board of Asan Medical Center, and received an excemption from IRB for reasons of retrospective medical record research. The Asan Medical Center's medical records were screened for patients who underwent an operation for RCC in January 1998December 2012. In total, 327 patients with pRCC types 1 and 2 or ccRCC at T1-stage who underwent a radical nephrectomy or nephron-sparing surgery at Asan Medical Center were reviewed.

All patients were evaluated at the time of their diagnosis, including physical examination, blood sampling, chest X-rays, abdominal and pelvic computed tomography (CT) or magnetic resonance imaging (MRI), and bone scans. Among these patients, 75 patients with $\mathrm{pRCC}$ and 252 patients with ccRCC at T1-stage were selected; of these pRCC patients, 37 were type 1 pRCC and 38 were type 2 pRCC. Most of the patients underwent nephron-sparing surgery. Only 2 patients of the 75 pRCC patients and one patient of the 252 ccRCC patients underwent a radical nephrectomy.

\section{Pathological evaluation}

The pathological stage was determined according to the 2002 Union Internationale Contre le Cancer TNM classification, and the pathological grade was determined according to Fuhrman classification (G1-G4). Tumor sizes were calculated by measuring the largest diameter of the surgically removed mass and histological subtypes were classified according to the Heidelberg classification. Papillary RCCs were further classified by an experienced pathologist as type 1 or type 2 and the RCCs were classified as type 1 if the cell contained papillae covered by a layer of small cuboidal cells with scanty cytoplasm. Type 2 pRCC was classified as such if it consisted of papillae covered by large eosinophilic cells arranged in a pseudostratified manner. Surgical methods (partial or radical nephrectomy) were determined by the surgeon after sufficient consideration regarding tumor characteristics, patient characteristics, and the surgeon's preferences.

\section{Follow-up strategy}

Abdominal and pelvic CT or MRI was performed at least every 6 months during the first year. Annual follow-up was done to trace the presence of local recurrence and distant metastasis. Blood sampling and chest X-rays were conducted during the follow-up periods. Chest CT and bone scans were also done if the surgeon deemed them necessary; the median 
follow-up duration was 95 months (interquartile range, 75.4119.3 months).

\section{Statistical analysis}

The tumor characteristics were compared using Pearson chi-square test (for categorical variables) and Student t-test (for continuous variables). Recurrence-free survival was evaluated using Kaplan-Meier analysis and the impact of pRCC subtype (types 1 and 2) on recurrence-free survival was also evaluated using Kaplan-Meier analysis. The impact of histological subtypes on overall survival was assessed using univariate and multivariate Cox analysis and all statistical analysis was performed using IBM SPSS Statistics ver. 21 (IBM SPSS, Armonk, NY, USA).

\section{RESULTS}

Among selected patients, 252 patients had ccRCC and 75 patients had pRCC. Among the pRCC patients, 37 had type 1 pRCC and 38 had type 2 pRCC. No difference was found for patients or tumor characteristics between pRCC and ccRCC except for age and Fuhrman grade. The mean patient ages were $51.2 \pm 12.2$ years in the ccRCC group and $56.2 \pm 12.7$ in the pRCC group. The pRCC group was older than the ccRCC group (56.2 years vs. 51.2 years, $\mathrm{p}=0.003$ ). The ratio of male to female patients was similar between the ccRCC and pRCC groups, and the hypertension and diabetes mellitus patient ratios were high in the pRCC group, but there was no significant statistical difference $(p=0.133$ for hypertension and $p=0.455$ for diabetes mellitus). The tumor size $(\mathrm{mm})$ was $24.4 \pm 12.6$ in ccRCCs and $23.7 \pm 10.9$ in pRCCs $(\mathrm{p}=0.885)$ and the Fuhrman grade was higher in pRCC $(\mathrm{p}<0.001)$ (Table 1).

There was no difference for patient and tumor characteristics between type $1 \mathrm{pRCC}$ and type $2 \mathrm{pRCC}$, but the Fuhrman grade was higher in type $2 \mathrm{pRCC}(\mathrm{p}=0.001)$. The mean patient age was $53.6 \pm 12.7$ years in the type 1 group and $58.9 \pm 10.8$ in the type 2 group. Patients with type 2 pRCC were older than those with type $1 \mathrm{pRCC}$ but there was no significant statistical difference between the 2 groups (58.9 years vs. 53.6 years, p= 0.074). The ratio of male to female patients was similar between the type 1 and type 2 pRCC groups. The ratio of patients with hypertension was higher in the type $1 \mathrm{pRCC}$ group than the type 2 pRCC group ( $32.4 \%$ vs. $26.3 \%$ ). The ratio of patients with diabetes mellitus was higher in the type 2 pRCC group than the type 1 pRCC group (13.2\% vs. $8.1 \%$ ) but this difference was not statistically significant $(\mathrm{p}=0.743$ in hypertension group and $\mathrm{p}=0.738$ in the diabetes mellitus group). The tumor size (mm) was $22.4 \pm 9.4$ for type 1 pRCCs and $25.0 \pm 12.2$ for type 2 pRCCs $(\mathrm{p}=0.425)$ (Table 2).

The 5-year recurrence-free survival rates of $\mathrm{pRCC}$ and ccRCC were $95.4 \%$ and $97.6 \%$, respectively. pRCC was worse than ccRCC for recurrence-free survival $(\mathrm{p}=0.008)$, the 5 -year overall survival rates of pRCC and ccRCC were $88.5 \%$ and $95.2 \%$, respectively $(p=0.32)$. There was no significant statistical difference in the overall survival rate between $\mathrm{pRCC}$ and ccRCC (Fig. 1). The 6-year recurrence-free survival rates of type $1 \mathrm{pRCC}$ and type $2 \mathrm{pRCC}$ were $95.3 \%$ and $93.5 \%$, respectively $(\mathrm{p}=0.526)$. The 5-year overall survival rates of type $1 \mathrm{pRCC}$ and type $2 \mathrm{pRCC}$ were $81.5 \%$ and $88.9 \%$, respectively $(p=0.701)$. There was no significant statistical difference between type $1 \mathrm{pRCC}$ and type $2 \mathrm{pRCC}$ for either recurrence-free survival or overall survival (Fig. 2).

Univariate and multivariate Cox proportional hazard models

Table 1. Comparison of characteristics between ccRCC and pRCC

\begin{tabular}{lrrr}
\hline \multicolumn{1}{c}{ Characteristic } & $\begin{array}{c}\text { Clear cell } \\
(\mathrm{n}=252)\end{array}$ & $\begin{array}{c}\text { Papillary } \\
(\mathrm{n}=75)\end{array}$ & p-value \\
\hline Age (yr) & $51.2 \pm 12.2$ & $56.2 \pm 12.7$ & 0.003 \\
Sex & & & 1.000 \\
$\quad$ Male & $193(76.6)$ & $57(76.0)$ & \\
$\quad$ Female & $59(23.4)$ & $18(24.0)$ & \\
Hypertension & $51(20.2)$ & $22(29.3)$ & 0.133 \\
Diabetes mellitus & $18(7.1)$ & $8(10.7)$ & 0.455 \\
ECOG-PS & & & 0.403 \\
0 & $246(97.6)$ & $75(100)$ & \\
1 & $5(2.0)$ & $0(0)$ & \\
2 & $1(0.4)$ & $0(0)$ & \\
Side & & & 0.084 \\
Right & $124(49.2)$ & $31(41.3)$ & \\
Left & $119(47.2)$ & $44(58.7)$ & \\
Tumor size (mm) & $24.4 \pm 12.6$ & $23.7 \pm 10.9$ & 0.885 \\
Fuhrman grade & & & $<0.001$ \\
1 & $18(7.1)$ & $7(9.3)$ & \\
2 & $161(63.9)$ & $28(37.3)$ & \\
3/4 & $73(29.0)$ & $34(45.3)$ & \\
Unknown & $0(0)$ & $6(8.0)$ & \\
T stage & & & 0.529 \\
T1a & $227(90.1)$ & $70(93.3)$ & \\
T1b & $25(9.9)$ & $5(6.7)$ & \\
\hline
\end{tabular}

Values are presented as mean \pm standard deviation or number (\%). ECOG-PS: Eastern Cooperative Oncology Group performance status. 
were used to compare overall survival, recurrence free survival and cancer specific survival in clear cell RCC and papillary RCC. Age (hazard ratio [HR], 1.069; $\mathrm{p}<0.001$ ) and recurrence (HR, 4.93; $\mathrm{p}<0.001)$ were predictors of overall survival in the multivariate analysis of all RCC types (Table 3). Subtype of tumor $(\mathrm{HR}, 6.830 ; \mathrm{p}<0.001)$ and size $(\mathrm{HR}, 1.053 ; \mathrm{p}=0.001)$

Table 2. Comparison of characteristics between pRCC types 1 and 2

\begin{tabular}{lrrr}
\hline \multicolumn{1}{c}{ Variable } & Type $1(\mathrm{n}=37)$ & Type $2(\mathrm{n}=38)$ & $\mathrm{p}$-value \\
\hline Age $(\mathrm{yr})$ & $53.6 \pm 12.7$ & $58.9 \pm 10.8$ & 0.074 \\
Sex & & & 0.837 \\
$\quad$ Male & $89(78.4)$ & $28(73.7)$ & \\
$\quad$ Female & $12(32.4)$ & $10(26.3)$ & \\
Hypertension & $3(8.1)$ & $5(13.2)$ & 0.738 \\
Diabetes mellitus & & & \\
ECOG-PS & $37(100.0)$ & $38(100.0)$ & \\
0 & & & 0.710 \\
Side & $14(37.8)$ & $17(44.7)$ & \\
Right & $23(62.2)$ & $21(55.3)$ & \\
Left & $22.4 \pm 9.4$ & $25.0 \pm 12.2$ & 0.425 \\
Tumor size (mm) & & & 0.001 \\
Fuhrman grade & $7(18.9)$ & $0(0.0)$ & \\
1 & $18(48.6)$ & $10(26.3)$ & \\
2 & $10(27.0)$ & $24(63.2)$ & \\
3 & $2(5.4)$ & $4(10.5)$ & \\
Unknown & & & 0.371 \\
T Stage & $36(97.3)$ & $34(89.5)$ & \\
T1a & $1(2.7)$ & $4(10.5)$ & \\
T1b & &
\end{tabular}

Values are presented as mean \pm standard deviation or number (\%). ECOG-PS: Eastern Cooperative Oncology Group performance status.

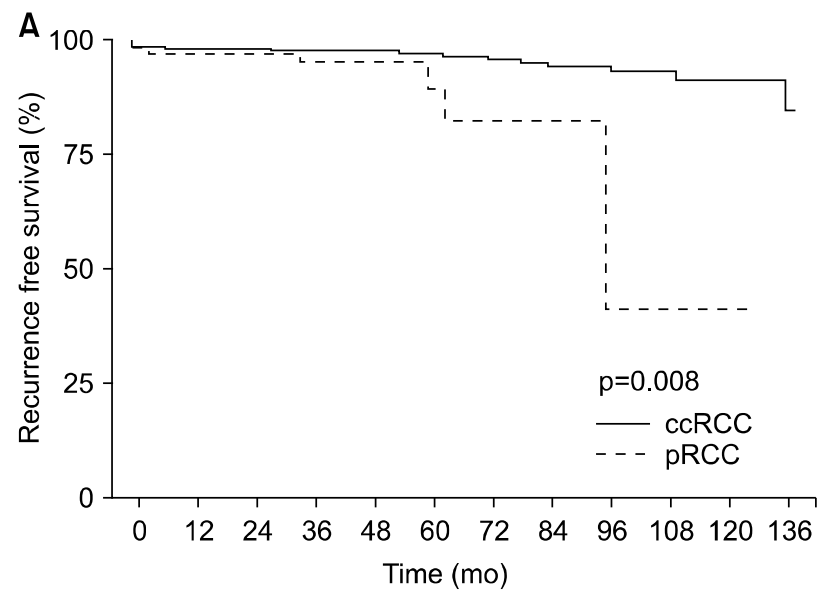

were predictors of recurrence free survival in multivariate analysis (Table 4). Only tumor size (HR, 1.071; $\mathrm{p}=0.004$ ) was predictors in the case of cancer specific survival (Table 5). A p-value of $<0.05$ was considered statistically significant.

\section{DISCUSSION}

In 1996, Heidelberg conference members made the first consensus in the identification of different types of RCC based on genetic differences. The Heidelberg classification system defines four different tumor types: clear cell, papillary, chromophobe, and collecting duct; there is also a group of tumors that remain unclassified. ${ }^{4}$ ccRCC is the most common histological subtype, accounting for $75 \%-80 \%$ of all RCCs. ${ }^{6,16}$ pRCC is the second most common subtype, accounting for $10 \%-15 \%$ of all malignant renal neoplasms. pRCC is histologically and genetically subclassified as types 1 and $2 .^{10,17-19}$

Tumor stage and nuclear grade are the most important prognostic factors for determining the oncologic outcomes of RCC. The prognostic significance of RCC subtype has been studied previously with variable patient populations; despite these multiple studies, the results are inconsistent. Therefore, it is controversial whether the histological subtype itself contributes to the oncologic outcome. A multicenter study with 4,063 patients from eight international centers reported a better 5-year cancer-specific survival rate for patients with pRCC (79\%) than for those with ccRCC (73\%) on univariate analysis. ${ }^{9}$ On multivariate analysis, the histological subtype was not an independent prognostic factor. A similar result was obtained in

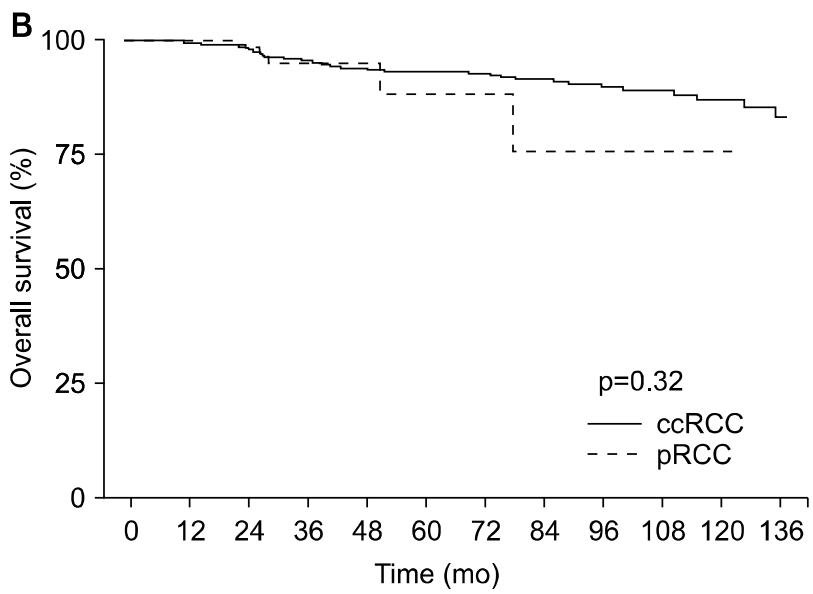

Fig. 1. Recurrence-free survival (A) and overall survival (B) between ccRCC and pRCC. RCC: renal cell carcinoma; pRCC: papillary RCC, ccRCC: clear cell RCC. 

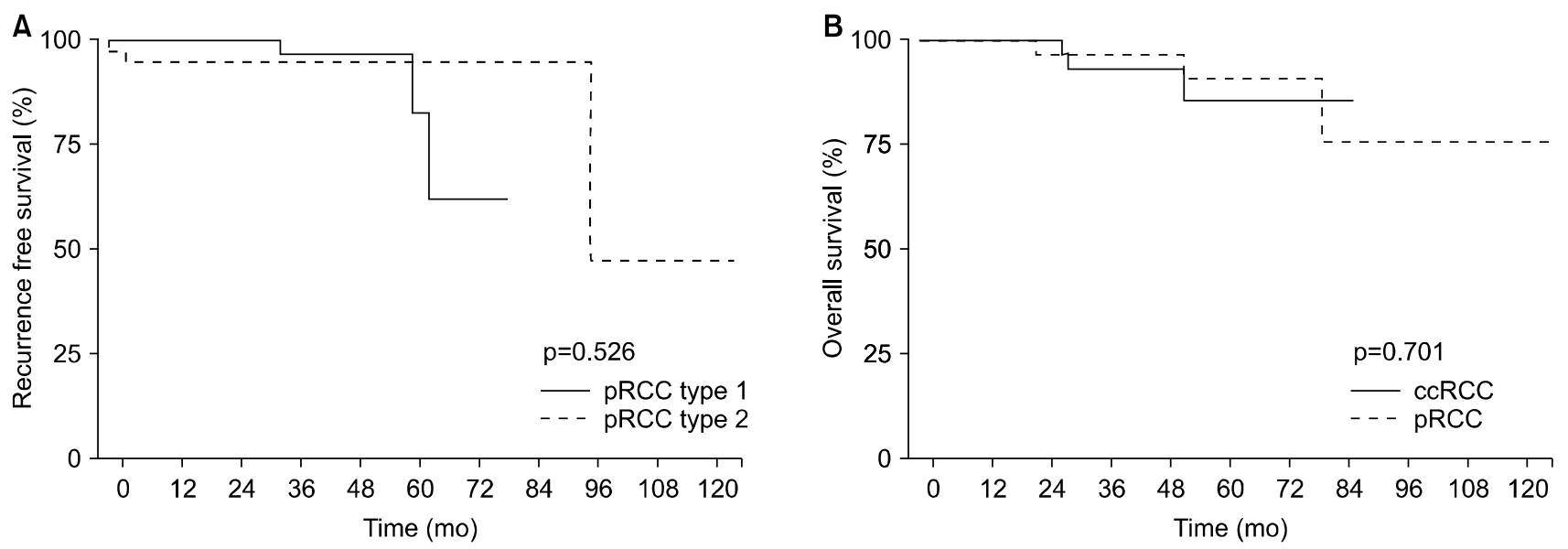

Fig. 2. Recurrence-free survival (A) and overall survival (B) between types 1 and 2 pRCC. RCC: renal cell carcinoma; pRCC: papillary RCC, ccRCC: clear cell RCC.

Table 3. Univariate and multivariate analysis for the overall survival in clear cell RCC and papillary RCC

\begin{tabular}{|c|c|c|c|c|c|c|}
\hline \multirow{2}{*}{ Variable } & \multicolumn{2}{|c|}{ Univariate } & \multirow{2}{*}{$\mathrm{p}$-value } & \multicolumn{2}{|c|}{ Multivariate } & \multirow{2}{*}{ p-value } \\
\hline & HR & $95 \% \mathrm{CI}$ & & HR & $95 \% \mathrm{CI}$ & \\
\hline Age, continuous & 1.060 & $1.03-1.09$ & 0.0000 & 1.069 & $1.038-1.102$ & $<0.001$ \\
\hline Sex, female vs. male & 0.720 & $0.3-1.73$ & 0.4580 & - & - & - \\
\hline Pathology type, pRCC vs. ccRCC & 1.590 & $0.63-3.97$ & 0.3240 & - & - & - \\
\hline Tumor size, continuous & 1.020 & $0.99-1.04$ & 0.1570 & - & - & - \\
\hline Fuhrman grade, $3 \& 4$ vs. $1 \& 2$ & 0.750 & $0.35-1.59$ & 0.4520 & - & - & - \\
\hline Recurrence, yes vs. no & 3.430 & $1.43-8.24$ & 0.0060 & 5.287 & $2.128-13.134$ & $<0.001$ \\
\hline
\end{tabular}

RCC: renal cell carcinoma, pRCC: papillary RCC, ccRCC: clear cell RCC, HR: hazard ratio, CI: confidence interval.

Table 4. Univariate and multivariate analysis for the recurrence free survival in clear cell RCC and papillary RCC

\begin{tabular}{|c|c|c|c|c|c|c|}
\hline \multirow{2}{*}{ Variable } & \multicolumn{2}{|c|}{ Univariate } & \multirow{2}{*}{ p-value } & \multicolumn{2}{|c|}{ Multivariate } & \multirow{2}{*}{ p-value } \\
\hline & HR & $95 \% \mathrm{CI}$ & & HR & $95 \% \mathrm{CI}$ & \\
\hline Age, continuous & 1.000 & $0.96-1.04$ & 0.928 & - & - & - \\
\hline Sex, female vs. male & 2.370 & $0.94-5.95$ & 0.066 & - & - & - \\
\hline Pathology type, pRCC vs. ccRCC & 5.860 & $1.99-17.3$ & 0.001 & 6.830 & $2.275-20.499$ & $<0.001$ \\
\hline Tumor size, continuous & 1.050 & $1.02-1.08$ & 0.002 & 1.053 & $1.021-1.086$ & 0.001 \\
\hline Fuhrman grade, $3 \& 4$ vs. $1 \& 2$ & 0.770 & $0.28-2.13$ & 0.611 & - & - & - \\
\hline
\end{tabular}

RCC: renal cell carcinoma, pRCC: papillary RCC, ccRCC: clear cell RCC, HR: hazard ratio, CI: confidence interval.

another study. ${ }^{20}$ Some studies have reported that type I pRCC has shown less aggressiveness. ${ }^{20-22}$ However, Yamanaka et al. ${ }^{12}$ found no significant difference between types 1 and 2 pRCC. $^{23}$ Consequently, the results are inconsistent.

The previous studies did not narrow the patients' pathologic stage down to T1 to compare oncological outcomes according to histological subtype, but this study compares oncological outcomes in just the T1-stage. In our analysis for patients with
T1-stage RCC, recurrence after surgery more commonly occurred in pRCC than ccRCC. There was no difference in overall survival between pRCC and ccRCC. The pRCC subtype (type 1 vs. type 2) had no impact on the recurrence-free survival or overall survival in Kaplan-Meier analysis.

Among the 75 pRCC patients in this study, 6 had tumor recurrence; of these, 3 were the type 1 subtype of pRCC, and the other 3 were in the type 2 pRCC subgroup. Meanwhile, 
Table 5. Univariate and multivariate analysis for the cancer specific survival in clear cell RCC and papillary RCC

\begin{tabular}{|c|c|c|c|c|c|c|}
\hline \multirow{2}{*}{ Variable } & \multicolumn{2}{|c|}{ Univariate } & \multirow{2}{*}{ p-value } & \multicolumn{2}{|c|}{ Multivariate } & \multirow{2}{*}{ p-value } \\
\hline & HR & $95 \% \mathrm{CI}$ & & HR & $95 \% \mathrm{CI}$ & \\
\hline Age, continuous & 1.000 & $0.94-1.07$ & 0.938 & & & \\
\hline Sex, female vs. male & 3.210 & $0.65-15.91$ & 0.153 & & & \\
\hline Pathology type, pRCC vs. ccRCC & 4.440 & $0.71-27.85$ & 0.112 & & & \\
\hline Tumor size, continuous & 1.070 & $1.02-1.12$ & 0.004 & 1.071 & $1.023-1.121$ & 0.004 \\
\hline Fuhrman grade, $3 \& 4$ vs. $1 \& 2$ & 1.020 & $0.19-5.6$ & 0.978 & & & \\
\hline
\end{tabular}

RCC: renal cell carcinoma, pRCC: papillary RCC, ccRCC: clear cell RCC, HR: hazard ratio, CI: confidence interval.

13 patients with ccRCCs had diagnosed tumor recurrence. All of the tumor recurrence case of type 1 pRCCs were T1a-stage. On the other hand, 2 patients were Tla-stage and 1 patient was T1b-stage in association with tumor recurrence case of type 2 pRCCs. In regards to tumor recurrence case of ccRCC, 10 patients were T1a-stage and 3 patients were T1b-stage. Every tumor recurrence occurred after nephron-sparing surgery regardless of subtype. In our study with local tumor recurrence, additional nephron-sparing surgery or radical nephrectomy were performed. In distant metastasis or the systemic recurrence of a tumor, targeted systemic therapy was performed with sunitinib (multitargeted receptor tyrosine kinase) or temsirolimus (mTOR kinase inhibitor). Even though pRCCs have higher recurrence rate, tumor size was important factor of recurrence and cancer specific survival. There was no significant difference between pRCCs and ccRCCs. Close observation is recommended in the case of pRCC patients because pRCCs recur more commonly than ccRCCs. Patients with large tumor size have worse prognosis since tumor size was predictors of cancer specific survival. Because recurrence also affect to overall survival, adequate tumor recurrence treatment is necessary. If additional tumor recurrence treatment was done, the overall survival was not affected by tumor classification although recurrence after surgery was more common in pRCC compared to ccRCC.

Our study had several important limitations; first, there are limitations in retrospective analysis. Another major limitation is the limited number of patients. Further analysis and results should be confirmed using larger prospective settings.

\section{CONCLUSION}

Histological subtype (pRCC vs. ccRCC) impacted recurrence-free survival but not overall survival in T1-stage. pRCC has an aggressive oncologic outcome concerning re- currence after surgery. The subtypes of pRCC (types 1 and 2) had no impact on either recurrence-free survival or overall survival. Close observation of recurrence and long-term follow-up is recommended particularly among patients with T1stage pRCC patients.

\section{CONFLICT OF INTEREST}

The authors claim no conflicts of interest.

\section{REFERENCES}

1. Jemal A, Siegel R, Xu J, Ward E. Cancer statistics, 2010. CA Cancer J Clin 2010;60:277-300.

2. Montironi R, Cheng L, Scarpelli M, Lopez-Beltran A. Pathology and genetics: tumours of the urinary system and male genital system: clinical implications of the 4th edition of the WHO classification and beyond. Eur Urol 2016;70: 120-3.

3. Thoenes W, Störkel S, Rumpelt HJ, Moll R. Cytomorphological typing of renal cell carcinoma--a new approach. Eur Urol 1990;18 Suppl 2:6-9.

4. Kovacs G, Akhtar M, Beckwith BJ, Bugert P, Cooper CS, Delahunt B, et al. The Heidelberg classification of renal cell tumours. J Pathol 1997;183:131-3.

5. Kovacs G, Fuzesi L, Emanual A, Kung HF. Cytogenetics of papillary renal cell tumors. Genes Chromosomes Cancer 1991; 3:249-55.

6. Cheville JC, Lohse CM, Zincke H, Weaver AL, Blute ML. Comparisons of outcome and prognostic features among histologic subtypes of renal cell carcinoma. Am J Surg Pathol 2003;27:612-24.

7. Kim H, Cho NH, Kim DS, Kwon YM, Kim EK, Rha SH, et al. Renal cell carcinoma in South Korea: a multicenter study. Hum Pathol 2004;35:1556-63.

8. Mancilla-Jimenez R, Stanley RJ, Blath RA. Papillary renal cell carcinoma: a clinical, radiologic, and pathologic study of 34 cases. Cancer 1976;38:2469-80. 
9. Patard JJ, Leray E, Rioux-Leclercq N, Cindolo L, Ficarra V, Zisman A, et al. Prognostic value of histologic subtypes in renal cell carcinoma: a multicenter experience. J Clin Oncol 2005;23:2763-71.

10. Schrader AJ, Rauer-Bruening S, Olbert PJ, Hegele A, Rustemeier J, Timmesfeld N, et al. Incidence and long-term prognosis of papillary renal cell carcinoma. J Cancer Res Clin Oncol 2009;135:799-805.

11. Cancer Genome Atlas Research Network, Linehan WM, Spellman PT, Ricketts CJ, Creighton CJ, Fei SS, et al. Comprehensive molecular characterization of papillary renal-cell carcinoma. N Engl J Med 2016;374:135-45.

12. Yamanaka K, Miyake H, Hara I, Inoue TA, Hanioka K, Fujisawa M. Papillary renal cell carcinoma: a clinicopathological study of 35 cases. Int J Urol 2006;13:1049-52.

13. Amin MB, Amin MB, Tamboli P, Javidan J, Stricker H, de-Peralta Venturina M, et al. Prognostic impact of histologic subtyping of adult renal epithelial neoplasms: an experience of 405 cases. Am J Surg Pathol 2002;26:281-91.

14. Gudbjartsson T, Hardarson S, Petursdottir V, Thoroddsen A, Magnusson J, Einarsson GV. Histological subtyping and nuclear grading of renal cell carcinoma and their implications for survival: a retrospective nation-wide study of 629 patients. Eur Urol 2005;48:593-600.

15. Margulis V, Tamboli P, Matin SF, Swanson DA, Wood CG. Analysis of clinicopathologic predictors of oncologic outcome provides insight into the natural history of surgically managed papillary renal cell carcinoma. Cancer 2008;112:1480-8.

16. Schrader AJ, Varga Z, Hegele A, Pfoertner S, Olbert P, Hofmann R. Second-line strategies for metastatic renal cell carcinoma: classics and novel approaches. J Cancer Res Clin Oncol 2006;132:137-49.

17. Herrmann E, Trojan L, Becker F, Wülfing C, Schrader AJ, Barth P, et al. Prognostic factors of papillary renal cell carcinoma: results from a multi-institutional series after pathological review. J Urol 2010;183:460-6.

18. Jiang F, Richter J, Schraml P, Bubendorf L, Gasser T, Sauter $\mathrm{G}$, et al. Chromosomal imbalances in papillary renal cell carcinoma: genetic differences between histological subtypes. Am J Pathol 1998;153:1467-73.

19. Zucchi A, Novara G, Costantini E, Antonelli A, Carini M, Carmignani $G$, et al. Prognostic factors in a large multi-institutional series of papillary renal cell carcinoma. BJU Int 2012;109:1140-6.

20. Beck SD, Patel MI, Snyder ME, Kattan MW, Motzer RJ, Reuter VE, et al. Effect of papillary and chromophobe cell type on disease-free survival after nephrectomy for renal cell carcinoma. Ann Surg Oncol 2004;11:71-7.

21. Delahunt B, Eble JN, McCredie MR, Bethwaite PB, Stewart $\mathrm{JH}$, Bilous AM. Morphologic typing of papillary renal cell carcinoma: comparison of growth kinetics and patient survival in 66 cases. Hum Pathol 2001;32:590-5.

22. Pignot G, Elie C, Conquy S, Vieillefond A, Flam T, Zerbib M, et al. Survival analysis of 130 patients with papillary renal cell carcinoma: prognostic utility of type 1 and type 2 subclassification. Urology 2007;69:230-5.

23. Waldert M, Haitel A, Marberger M, Katzenbeisser D, Ozsoy M, Stadler E, et al. Comparison of type I and II papillary renal cell carcinoma (RCC) and clear cell RCC. BJU Int 2008; 102:1381-4. 